\title{
CAPÍTULO 16: A INSERÇÃO DA MANTA DE CARNEIRO NA AGROINDÚSTRIA DE PEQUENO PORTE: UM RELATO DE EXPERIÊNCIA
}

\section{CAPÍTULO 16: EL INSERTO DE LA MANTA DE OVEJAS EN LA PEQUEÑA AGROINDUSTRIA: UN INFORME DE EXPERIENCIA}

\section{CHAPTER 16: THE INSERT OF THE SHEEP BLANKET IN THE SMALL AGROINDUSTRY: AN EXPERIENCE REPORT}

\begin{abstract}
Francisca Giselle da Cruz; ; João Paulo Arcelino do Rêgo²; Priscila Izidro de Figueirêdo ${ }^{3}$; Wagner Pessanha Tamy ${ }^{4}$; Alfredo Tavares Fernandez ${ }^{5}$
\end{abstract}

\section{INTRODUÇÃO}

\section{DOI: https://doi.org/10.31692/978-65-88970-19-5.237-241}

A manta de carneiro pode ser conceituada como um produto cárneo salgado, proveniente da desossa e manteação de carcaças ovinas e caprinas inteiras, submetida às etapas de salga seca e secagem. O sal e a carne são os únicos ingredientes utilizados para obtenção da manta. O que ocorre basicamente na secagem é a difusão da umidade do interior para o exterior da carne e a difusão do sal na carne, com consequente diminuição da umidade do produto (COSTA et al., 2010).

A discussão sobre a dificuldade de acesso de agricultoras(es) familiares, representantes da agroindústria rural de pequeno porte, ao mercado de produtos de origem animal não é nova (LOPES et al., 2017). A agroindustrialização e o acesso aos mercados fazem parte dos grandes desafios enfrentados pela agricultura familiar. As famílias que comercializam regularmente sua produção estão em sua maioria submetidas às cadeias produtivas dominadas pelas grandes agroindústrias (PREZZOTO, 2016).

Vale a pena ressaltar que, nos estabelecimentos da Agricultura Familiar, a população ocupada se reduziu em 2,166 milhões de pessoas. No entanto, nos estabelecimentos que não caracterizados dessa forma, a oferta de postos de trabalho seguiu um rumo oposto: de 2006 para 2017, a população ocupada nesse tipo de estabelecimentos ganhou mais 702,9 mil trabalhadores. No Censo Agropecuário de 2017, 3.897 .408 estabelecimentos atenderam aos critérios e foram classificados como agricultura familiar, o que representa $77 \%$ dos

\footnotetext{
${ }^{1}$ Aluna do curso de Especialização em Produção animal, higiene e tecnologia de POA, UFF, franciscagiselle@id.uff.br; ${ }^{2}$ Professor do IFCE campus Boa Viagem, joaopaulo.rego@gmail.com; ${ }^{3}$ Aluna do curso de Doutorado em Biociência Animal da UFRPE, priscila.izoot@gmail.com; ${ }^{4}$ Professor da UFF, Co-orientador, wagnertamy@id.uff.br; ${ }^{5}$ Professor da UFF, Orientador, afernandez@id.uff.br
} 


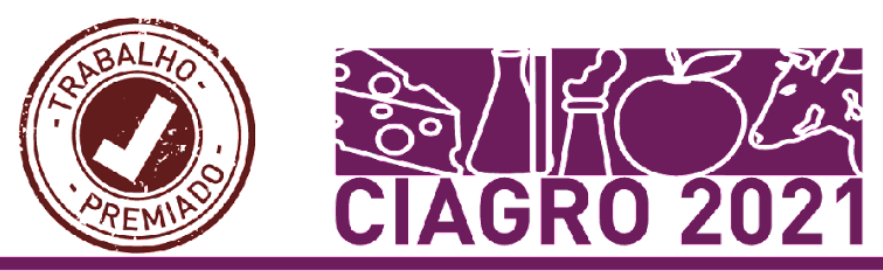

estabelecimentos agropecuários levantados pelo censo. Ocupavam uma área de 80,9 milhões de hectares, ou seja, $23 \%$ da área total dos estabelecimentos agropecuários brasileiros. Nos estabelecimentos classificados como de agricultura familiar o total de pessoas ocupadas em 30 de setembro de 2017 foi de 10,1 milhões de pessoas; 67\% do total, nestes estabelecimentos a média de pessoas ocupadas era de 2,6. A agricultura familiar foi responsável por 23\% do valor total da produção dos estabelecimentos (IBGE, 2019).

Diante do exposto, o presente trabalho objetivou relatar um relato de experiência, oriundo de uma oficina (4h/a) realizada no evento de extensão Agri \& Pec Cariri, em outubro de 2019, realizada na seção de agroindústria do Instituto de Educação, Ciência e Tecnologia do Ceará, campus Crato, sobre a obtenção da manta de carneiro e a inserção da mesma para agoindústria de pequeno porte.

\section{METODOLOGIA}

Uma oficina (4h/a) foi realizada sobre a obtenção da manta de carneiro, prática tradicional, cultural e bastante realizada na Região dos Inhamuns, CE e em Petrolina-PE. As seguintes problemáticas foram levantadas e discutidas: Como efetivar a inserção da manta de carneiro, na agroindústria de pequeno porte? Como a realização desta prática pode auxiliar na construção do conhecimento para o pequeno agricultor?

O presente estudo foi de natureza qualitativa e descritiva, seguindo a proposta de Marconi e Lakatos (2013). Vale elucidar que este trabalho foi fundamentado na elaboração do relato de experiência de uma oficina, proferida no evento de extensão Agri \& Pec Cariri, na seção de agroindústria do IFCE campus Crato-CE, em outubro de 2019, sobre a obtenção da manta de carneiro. Nesse sentido, a proposta deste estudo em repassar a prática de elaboração da manta de carneiro foi efetiva, envolvendo públicos-alvo interno e externo às atividades acadêmicas do IFCE campus Crato, totalizando em 20 participantes.

\section{RELATO DE EXPERIÊNCIA}

Os participanete tiveram a oportunidade em acompanhar a oficina, proferida pelo professor Dr. João Paulo. Na oportunidade, o rendimento tecnológico foi calculado, pela diferença de peso $(\mathrm{kg})$ da carcaça ovina in natura e resfriada $\left(4^{\circ} \mathrm{C} / 24 \mathrm{~h}\right.$ após o abate), com o peso $(\mathrm{kg})$ da carcaça manteada, posteriormente adicionada de tempero seco, composto de sal comum, alho desidratado em pó e pimenta do reino em pó, aplicados diretamente sobre a manta, à gosto, assim como o vinho tinto doce. Houve uma redução de $6 \mathrm{~kg}$, em relação ao 


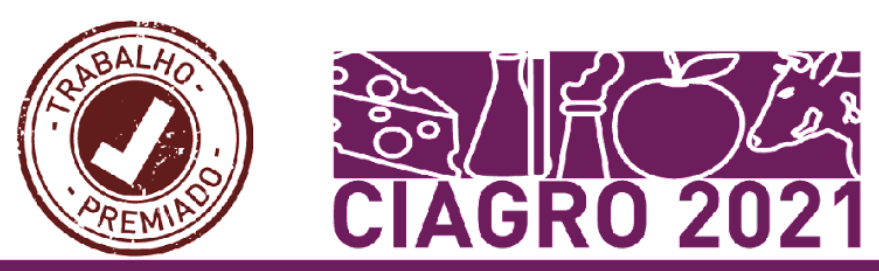

peso da carcaça in natura $(18 \mathrm{~kg})$ e da manta obtida desossada $(12 \mathrm{~kg})$. Cabe ressaltar, que a manta ovina é um produto típico da região Nordeste, amplamente consumido, sendo processado a partir da desossa, salga e secagem de carcaças inteiras de ovinos ou caprinos, recebendo esta denominação pela aparência final de uma manta ou lençol (FÉLIX et al., 2011).

De acordo com Costa et al. (2010) os rendimentos das mantas após a desossa inicial das carcaças de animais adultos (de 13 a 24 e de 25 a 36 meses de idade) são similares, com valores de 74,8 e $75,1 \%$, enquanto os das mantas provenientes de carcaças de animais mais jovens alcançam em média 71,5\%. Estes valores são atribuídos às maiores quantidades de tecidos musculares e adiposos nas carcaças de animais com maiores faixas etárias, representadas, em grande parte, por carcaças originadas de fêmeas adultas.

A figura 1 apresenta a obtenção da manta de carneiro.

Figura 01: Obtenção da manta de carneiro

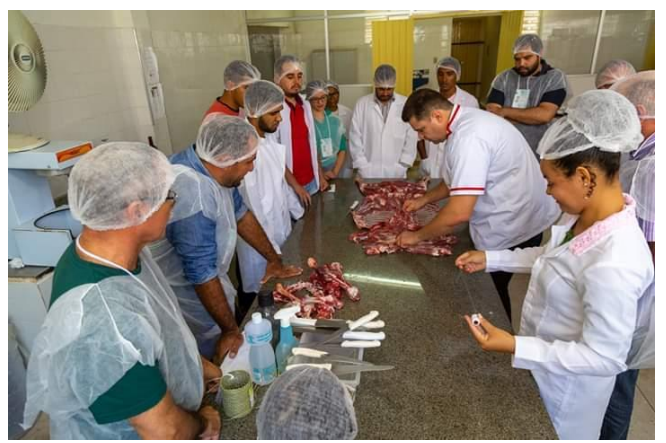

Fonte: Própria (2019).

Como efetivar a inserção da manta de carneiro, na agroindústria de pequeno porte? Como a realização desta prática pode auxiliar na construção do conhecimento para o pequeno agricultor? Então, para as pequenas agroindústrias, a importância da implantação do Sistema Unificado de Atenção à Sanidade Agropecuária, SUASA é a facilitação da inserção dos produtos no mercado formal (local, regional e nacional). Este é um importante aspecto, pois possibilita a comercialização dos produtos em todo o território nacional, quando inspecionados por qualquer uma das instâncias do SUASA pelos municípios, estados, Distrito Federal ou União. Vale destacar mesmo que, a agroindústria de pequeno porte solicite a adesão de estados e municípios ao Sistema Brasileiro de Inspeção de Produtos de Origem Animal, SISBI/SUASA, os agricultores e agricultoras familiares devem registrar a agroindústria em um dos serviços de inspeção municipal ou estadual, SIM ou SIE, por se tratar de um produto de origem animal, a manta de carneiro e consequentemente obter o selo 
ARTE (PREZZOTO, 2016).

Contudo, a recém publicada Instrução Normativa ${ }^{\circ} 61$, de 16 de novembro de 2020 do Ministério da Agricultura, Pecuária e Abastecimento, MAPA que entrou em vigor desde $1^{\circ}$ de dezembro de 2020, que resolve estabelecer, em todo o território nacional, o Regulamento para enquadramento dos produtos cárneos e artesanais, necessário à concessão do Selo ARTE, as exigências de Boas Práticas Agropecuárias e de Fabricação que são aquelas previstas nos programas de saúde animal e do Serviço de Inspeção Oficial (BRASIL, 2020).

Contudo, a implantação de pequenas agroindústrias é uma das alternativas econômicas para a permanência dos agricultores e agricultoras familiares no meio rural. Para eles, a industrialização dos produtos agropecuários é um grande desafio, mas não se constitui em uma novidade. Isto já faz parte da sua própria história e cultura, destinado ao consumo familiar e/ou a venda de excedentes (PREZZOTO, 2016). Nesse caso, cabe a nós, como corpo técnico difundir esta tecnologia de baixo custo e de fácil acesso, desde que, o manipulador de alimentos seja bem treinado, em Boas Práticas de Fabricação e elaboração da manta, além da instrução legal, por meio de certificação deste produto, perante a legislação sanitária vigente.

Houve uma excelente aceitação da oficina, por meio dos vinte participanetes, onde alguns deles já trabalham na área de cortes cárneos, da carne ovina, e também são agricultores familiares. Com isto, pode-se afirmar que a socialização e a troca dos conhecimentos colaboram para um movimento de contribuição para a vida profissional dos discentes e público externo, com o planejamento de atividades e com a reflexão na forma de registros que permitem a mobilização de saberes disciplinares, curriculares e pedagógicos, conforme destaca Tardif (2002), os quais podem fundamentar a formação do futuro profissional e contribuir significativamente na constituição de seus saberes.

\section{CONCLUSÕES}

A experiência de extensão vivenciada foi exitosa, estudos sobre rendimento da manta, obtenção dos cortes para esepeto poderão ser realizados em estudos futuros. A obtenção da manta ovina faz parte do cotidiano do nordestino, principalmente nos estados do Ceará e Pernambuco e, elucidar esta prática por meio da legalização da atividade, Inspeção sanitária e 
adessão ao selo ARTE é sem dúvidas, uma tarefa que se faz necessária ser conduzida por nós, técnicos da área, para que assim, a agroindústria de pequeno porte possa atuar com excelência, qualidade e segurança dos alimentos de origem animal elaborados.

\section{REFERÊNCIAS}

BRASIL, Ministério da Agricultura, Pecuária e Abastecimento. Instrução Normativa ${ }^{\circ} 61$, de 16 de novembro de 2020. Resolve estabelecer, em todo o território nacional, o Regulamento para enquadramento dos produtos cárneos e artesanais, necessário à concessão do selo ARTE, na forma desta Instrução Normativa. Diário Oficial [da] República Federativa do Brasil, Brasília, DF, p. 147, 18 nov. Seção 1. 2020.

COSTA, R. G.; MADRUGA, M. S.; MEDEIROS, G. R.; VOLTOLINI, T. V.; DUARTE, T. F.; PEDROSA, N. D. A. Manta de Petrolina: uma alternativa para agregar valor às carnes caprina e ovina. Petrolina: MCT/INSA, 2010. 109p.

FÉLIX, S. S. D. S.; FERNANDES, T. D.; ALVES, F. S. F., LÔBO, K. M.; GUERRA, I. C. D.; MADRUGA, M. S. Avaliação físico-química da manta ovina salgada do Tauá. $5^{\circ}$ Simpósio Internacional sobre Caprinos e Ovinos de Corte, $5^{\circ}$ SINCORTE. Feira Nacional do Agronegócio de Caprino-ovinocultura de corte - FENACORTE. João Pessoa-PB, 24 a 28 de outubro de 2011.

IBGE. Instituto Brasileiro de Geografia e Estatística. Censo Agro 2017: população ocupada nos estabelecimentos agropecuários cai 8,8\%. 2006. 25 de outubro de 2019. Disponível em:

https://agenciadenoticias.ibge.gov.br/agencia-sala-de-imprensa/2013-agencia-de-noticias/relea ses/25789-censo-agro-2017-populacao-ocupada-nos-estabelecimentos-agropecuarios-cai-8-8. Acesso em: 17 abr. 2021.

MARCONI, M. A; LAKATOS, E. M. Fundamentos de metodologia científica. $5^{\text {a }}$. ed. São Paulo: Editora Atlas, 2006.

PREZZOTO, L. L. Agroindústria da agricultura familiar: regularização e acesso ao mercado. Brasília, DF: CONTAG .60 p. 2016.

TARDIF, M. Saberes docentes e saberes docentes e formação profissional. Petrópolis:

Vozes, 2002. 